\title{
Central pancreatectomy for early-stage pancreatic ductal adenocarcinoma: a single-center case-control study
}

\author{
Hao Gao ${ }^{1,2} \cdot$ Tongtai Liu ${ }^{1,2} \cdot$ Guangfu Wang ${ }^{1,2} \cdot$ Yong Gao ${ }^{1,2} \cdot$ Lingdi Yin $^{1,2} \cdot$ Yunpeng Peng ${ }^{1,2} \cdot$ Nan Lyu ${ }^{1,2}$. \\ Kai Zhang ${ }^{1,2} \cdot$ Wentao Gao ${ }^{1,2} \cdot$ Junli Wu ${ }^{1,2} \cdot$ Kuirong Jiang ${ }^{1,2} \cdot$ Jishu Wei ${ }^{1,2}$ (D) Yi Miao ${ }^{1,2}$
}

Received: 22 November 2018 / Accepted: 18 February 2019 / Published online: 2 March 2019

(C) The Author(s) 2019

\begin{abstract}
Purpose Central pancreatectomy (CP) has been applied for treating benign and low-grade malignant tumors in pancreatic neck, but studies regarding $\mathrm{CP}$ for pancreatic ductal adenocarcinoma (PDAC) are quite limited. We aimed to investigate the role of central pancreatectomy in the treatment of PDAC in the neck of the pancreas.

Methods Patients who underwent CP at our hospital between 2009 and 2016 were identified. Patients treated by distal pancreatectomy (DP) were matched according to the tumor size, location, and staging. The surgical and survival outcomes were compared between the $\mathrm{CP}$ and DP groups.

Results Nine patients had CP. Five (56\%) had postoperative complications and three (33\%) had clinically significant (grade B + C) fistula. No significant difference was found between the CP and DP groups for the rate of overall morbidity, pancreatic fistula, reoperation, and readmission. Tumor size was smaller in the $\mathrm{CP}$ group compared to the DP group. The mortality of both groups was zero. The median postoperative survival was similar between the two groups (20.4 months for CP vs 19.4 months for DP, $P=0.842$ ).

Conclusions $\mathrm{CP}$ is safe for patients with small PDAC at the neck of the pancreas. Considering the good preservation of pancreatic endocrine and exocrine functions, $\mathrm{CP}$ could be considered as an alternative procedure for single small PDAC in pancreatic neck.
\end{abstract}

Keywords Central pancreatectomy $\cdot$ Morbidity $\cdot$ Pancreatic ductal adenocarcinoma $\cdot$ Pancreatic fistula $\cdot$ Postoperative survival

\section{Introduction}

Neoplasms located in the neck of pancreas pose a challenge to pancreatic surgeons. In general, tumors in this location are resected by distal pancreatectomy (DP) [1]. However, DP removes a significant amount of normal pancreatic parenchyma and may cause endocrine and exocrine insufficiency [2-4]. Central pancreatectomy $(\mathrm{CP})$ has been proposed as an

Hao Gao and Tongtai Liu contributed equally to this work. Jishu Wei and Yi Miao contributed equally to this article and are considered as joint corresponding authors.

Jishu Wei

weijishu@njmu.edu.cn

Yi Miao

miaoyi@njmu.edu.cn

1 Pancreas Center, The First Affiliated Hospital of Nanjing Medical University, 300 Guangzhou Road, Nanjing 210029, China

2 Pancreas Institute of Nanjing Medical University, Nanjing, China alternative to DP for benign or low-grade malignant tumors in the neck of the pancreas because it spares normal pancreatic tissue and potentially preserves the function [5]. In addition, CP was also applied to treat metastatic lesions to the pancreas $[6,7]$. Central pancreatectomy, also known as middle pancreatectomy or medial pancreatectomy, was first performed by Dagradi and Serio [8] in patients with oncological indication in 1982. Since then, an increasing number of cases have been reported. Some systematic reviews and meta-analyses [9-11] showed that $\mathrm{CP}$ could decrease the risk of exocrine failure and impairment of endocrine function than DP, although it was associated with a slightly higher postoperative morbidity.

In recent years, data in favor of limited resections for pancreatic tumors have been accumulating. Enucleation has been reported to be alternative procedure to radical pancreatectomy [12-14] and patients treated by pyloruspreserving pancreaticoduodenectomy (PPPD) could achieve similar long-term survival as patients undergoing pancreaticoduodenectomy (PD) [15]. However, there is concern that $\mathrm{CP}$ is not an adequate oncological procedure 
for pancreatic ductal adenocarcinoma (PDAC) [16, 17]. Studies regarding $\mathrm{CP}$ for PDAC are quite limited. With the advancement of radiology, more early-stage PDAC are detected. In this context, there is a need to study the role of CP in the treatment of small PDAC.

Therefore, this case-control study was performed to analyze operative morbidity, mortality, and, more importantly, survival outcomes to evaluate the real effect, safety, and feasibility of CP in PDAC.

\section{Material and methods}

\section{Patient database}

A prospectively maintained pancreatectomy database was reviewed retrospectively to identify all eligible patients between November 2009 and December 2016. The study was approved by the Institutional Review Board of the First Affiliated Hospital of Nanjing Medical University. Preoperative imaging workup included computed tomography, magnetic resonance imaging, and/or endoscopic ultrasonography with fine-needle aspiration. The following criteria were used to select patients: (1) patients with PDAC undergoing CP or DP; (2) solitary PDAC localized in the pancreatic neck. The exclusion criteria included (1) incomplete medical record or follow-up data and (2) the operation involved resection of adjacent organs or vessels. Patient records were reviewed to obtain the demographic features, clinical characteristics, intraoperative and postoperative data, and pathological findings. Follow-up was based on radiologic, clinical, and laboratory assessments every 6-12 months.

Postoperative morbidity, including postoperative pancreatic fistula (POPF) [18], delayed gastric emptying (DGE) [19], chyle leak [20], and hemorrhage [21], was assessed according to the definitions of International Study Group of Pancreatic Surgery. Postoperative mortality was defined as death before hospital discharge or within 30 days after the operation. Readmission was defined as another admission within 30 days after the last hospital discharge. Reoperation was defined as operation again before hospital discharge or within 30 days after the last operation. Tumor, node, and metastasis (TNM) staging was classified by the American Joint Committee on Cancer staging manual, 8th edition [22].

\section{Surgical procedure}

The decision to perform a CP or DP was finally based on tumor location and size during operation at the surgeons' discretion. A CP was performed according to previously described techniques [5]. The proximal pancreatic remnant was oversewn after ligating the main pancreatic duct. For distal pancreatic remnant, an end-to-side one-layer interrupted pancreaticojejunostomy was performed for reconstruction. In the DP group, splenectomy and lymph node dissection were routinely performed. Besides, the pancreas end was sutured interruptedly after separate ligation of the main pancreatic duct. All surgeries were done using open laparotomy. Two closed suction drains were routinely placed in the end of surgery.

\section{Statistical analysis}

Categorical variables were presented as numbers and percentages. Continuous variables were expressed as mean \pm standard deviation (SD) or median (interquartile range) whenever appropriate. Categorical variables were compared using the Pearson $\chi^{2}$ test and Fisher exact test when the cell count was $<5$. Normally distributed continuous variables were compared using the Student $t$ test, and the Mann-Whitney $U$ test was used for nonnormally distributed variables. Survival analyses were conducted using the Kaplan-Meier method with the log-rank test. A $P$ value less than 0.05 was considered statistically significant. All statistical analyses were performed using the IBM SPSS software version 13.0 (SPSS Inc., IL, USA).

\section{Results}

\section{Patient and tumor characteristics}

Patient and tumor characteristics are shown in Table 1. A total of 64 patients were enrolled in the present study with 9 patients undergoing $\mathrm{CP}$ and 55 with DP. In the $\mathrm{CP}$ group, patients had a mean age of $65 \pm 8.0$ years, and four $(44 \%)$ of nine patients were men. The most frequent symptom was abdominal pain or discomfort (78\%). Of the 55 patients undergoing DP, $30(55 \%)$ were men and $25(45 \%)$ were women with a mean age of $63 \pm 9.2$ years. Similarly, the most common symptom was abdominal pain or discomfort (53\%), followed by an incidental finding (40\%).The two groups were well matched in demographics. No significant difference was found between the two groups in CA19-9 $(P=0.170)$, TNM staging $(P=0.501), \mathrm{N}$ staging $(P=0.809)$, and differentiation $(P=0.151)$. The patients undergoing DP had larger tumor diameter $(P=0.010)$ and higher $\mathrm{T}$ staging $(P=0.016)$ than patients undergoing $\mathrm{CP}$. The $\mathrm{CP}$ group had fewer but not significant $(P=0.063)$ lymph nodes resected than the DP group.

\section{Surgical outcomes}

Surgical outcomes, including intraoperative and postoperative data, are detailed in Table 2. The mean operative time of the CP group was $214 \pm 53 \mathrm{~min}$, which was similar to that of the DP group (177 $\pm 69 \mathrm{~min}, P=0.130)$. No significant difference 
Table 1 Patient and tumor characteristics

\begin{tabular}{|c|c|c|c|}
\hline & $\mathrm{CP}(n=9)$ & $\mathrm{DP}(n=55)$ & $P$ \\
\hline Gender & & & 0.839 \\
\hline Male & $4(44 \%)$ & $30(55 \%)$ & \\
\hline Female & $5(56 \%)$ & $25(45 \%)$ & \\
\hline Age (year) & $65 \pm 8.0$ & $63 \pm 9.2$ & 0.649 \\
\hline Symptom & & & - \\
\hline Abdominal pain or discomfort & $7(78 \%)$ & $29(52 \%)$ & \\
\hline Back pain & 0 & $2(4 \%)$ & \\
\hline Weight loss & 0 & $2(4 \%)$ & \\
\hline Incidental finding & $2(22 \%)$ & $22(40 \%)$ & \\
\hline CA19-9 (U/mL) & $14.4(1.7-300.2)$ & $86.4(27.6-204.2)$ & 0.170 \\
\hline Greatest tumor diameter $(\mathrm{cm})$ & $1.9 \pm 0.6$ & $3.3 \pm 1.5$ & 0.010 \\
\hline TNM staging & & & 0.466 \\
\hline IA & $3(33 \%)$ & $11(20 \%)$ & \\
\hline IB & $3(33 \%)$ & $20(36 \%)$ & \\
\hline IIA & 0 & $4(7 \%)$ & \\
\hline IIB & $3(34 \%)$ & $18(33 \%)$ & \\
\hline III & 0 & $2(4 \%)$ & \\
\hline T staging & & & 0.016 \\
\hline $\mathrm{T} 1$ & $6(67 \%)$ & $15(27 \%)$ & \\
\hline $\mathrm{T} 2$ & $3(33 \%)$ & $29(53 \%)$ & \\
\hline $\mathrm{T} 3$ & 0 & $11(20 \%)$ & \\
\hline $\mathrm{N}$ staging & & & 0.809 \\
\hline No & $6(67 \%)$ & $35(64 \%)$ & \\
\hline N1 & $3(33 \%)$ & $18(33 \%)$ & \\
\hline $\mathrm{N} 2$ & 0 & $2(3 \%)$ & \\
\hline Lymph nodes resected & $1(0-6)$ & $5(2-9)$ & 0.063 \\
\hline Differentiation & & & 0.151 \\
\hline High & $1(11 \%)$ & 0 & \\
\hline High-medium & 0 & $4(7 \%)$ & \\
\hline Medium & $5(56 \%)$ & $19(35 \%)$ & \\
\hline Medium-low & $3(33 \%)$ & $29(53 \%)$ & \\
\hline Low & 0 & $3(5 \%)$ & \\
\hline
\end{tabular}

$C P$, central pancreatectomy; $D P$, distal pancreatectomy was observed in blood loss $(P=0.477)$ and blood transfusion $(P=0.364)$ between the CP and DP groups. Mortality of both groups was zero. We saw no statistical difference of the rates of overall morbidity, overall POPF, biochemical leak, clinically significant (grade $\mathrm{B}+\mathrm{C}$ ) pancreatic fistula, DGE, abdominal collections, and readmission between the CP and DP groups. No difference was found in chyle leak, hemorrhage, and pulmonary complications between the two groups. The median postoperative hospital stay was similar between the CP and DP groups [13 (10.5-18.5) vs 12 (10.0-16.0), $P=$ 0.628]. No patient underwent reoperation in the CP group, while one patient in the DP group underwent reoperation due to bleeding caused by grade $\mathrm{C}$ pancreatic fistula. The DP group had a higher trend of R0 rate compared with the CP group (93\% vs 67\%, $P=0.052$ ).

\section{Long-term results}

The follow-up data were complete and updated in May 2018. A total of 64 patients were included in the survival analysis. The median follow-up period for the CP and DP groups was 39.5 (24.7-74.8) and 23.5 (17.836.2) months, respectively. The $\mathrm{CP}$ group had a median postoperative overall survival of $20.4(12.6-41.5)$ months (detailed in Table 3), while the survival for the DP group was 19.4 (12.9-31.5) months. As shown in Fig. 1, no significant difference was observed regarding postoperative overall survival between the two groups (log-rank $P=$ 0.842 ). The rate of adjuvant chemotherapy was $45 \%$ in the $\mathrm{CP}$ group and $67 \%$ in the DP group. Because the information on adjuvant chemotherapy of three patients in the 
Table 2 Intraoperative and postoperative data

\begin{tabular}{|c|c|c|c|}
\hline & $\mathrm{CP}(n=9)$ & $\mathrm{DP}(n=55)$ & $P$ \\
\hline Operative time (min) & $214 \pm 53$ & $177 \pm 69$ & 0.130 \\
\hline Blood loss (mL) & $200(100-500)$ & $200(100-200)$ & 0.477 \\
\hline Blood transfusion & $3(33 \%)$ & $8(15 \%)$ & 0.364 \\
\hline Mortality & 0 & 0 & - \\
\hline Overall morbidity & $5(56 \%)$ & $20(36 \%)$ & 0.468 \\
\hline Overall POPF & $5(56 \%)$ & $24(44 \%)$ & 0.761 \\
\hline Biochemical leak & $3(33 \%)$ & $18(33 \%)$ & 1.000 \\
\hline Grade B + C POPF & $3(33 \%)$ & $6(11 \%)$ & 0.202 \\
\hline Grade B & 3 & 5 & \\
\hline Grade C & 0 & 1 & \\
\hline DGE & $2(22 \%)$ & $6(11 \%)$ & 0.683 \\
\hline Chyle leak & 0 & $5(9 \%)$ & 1.000 \\
\hline Hemorrhage & 0 & $1(2 \%)$ & 1.000 \\
\hline Abdominal collections & $1(11 \%)$ & $5(9 \%)$ & 1.000 \\
\hline Pulmonary complications & 0 & $5(9 \%)$ & 1.000 \\
\hline Postoperative hospital stay (day) & $13(10.5-18.5)$ & $12(10.0-16.0)$ & 0.628 \\
\hline Readmission & $2(22 \%)$ & $4(7 \%)$ & 0.196 \\
\hline Reoperation & 0 & $1(2 \%)$ & 1.000 \\
\hline Margin & & & 0.052 \\
\hline R0 & $6(67 \%)$ & $51(93 \%)$ & \\
\hline R1 & $3(33 \%)$ & $4(7 \%)$ & \\
\hline Chemotherapy & & & - \\
\hline Yes & $4(45 \%)$ & $37(67 \%)$ & \\
\hline No & $2(22 \%)$ & $16(29 \%)$ & \\
\hline NA & $3(33 \%)$ & $2(4 \%)$ & \\
\hline
\end{tabular}

$C P$, central pancreatectomy; $D P$, distal pancreatectomy; $D G E$, delayed gastric emptying; $N A$, not available; $P O P F$, postoperative pancreatic fistula
CP group and 2 patients in the DP group was not available, statistical analysis could not be performed.

\section{Discussion}

There is a trend of limited resections for pancreatic tumors without compromising the oncologic principles. For instance, solitary benign or low-grade malignant pancreatic tumors can be resected by enucleation [12-14]. A Cochrane metaanalysis [15] suggested no relevant difference in mortality, morbidity, and survival between PPPD and PD. In general, $\mathrm{CP}$ has the following potential advantages [23]: (1) parenchyma preserving to reduce endocrine and exocrine insufficiency even with a slightly higher morbidity rate; (2) spleen preserving.

One of the major concerns of CP is its high operative morbidity rate, particularly POPF. As Table 4 presents, we summarized recent studies on CP. The table indicated that the CP group had a slightly higher postoperative morbidity but better preservation of pancreatic function than the DP group. The overall morbidity of the $\mathrm{CP}$ group ranges from 28 to $72 \%$. Overall POPF ranges from 7 to $63 \%$ with clinically significant (grade B + C) POPF ranging from 16 to $44 \%$. Such a large range of POPF rate may be attributed to different assessments and definitions of POPF. Operative mortality is also low and many studies have reported zero mortality. In this study, the overall morbidity of the $\mathrm{CP}$ group was $56 \%$. The overall POPF was $56 \%$, yet the grade B + C POPF accounted for $33 \%$, which was consistent with the reported findings. Fortunately, no postoperative deaths occurred in the series. From the viewpoint of short-term results, these data reflected that $\mathrm{CP}$ was a safe procedure with morbidity and mortality consistent with other reported findings.

In this case-control study, demographic features, CA19-9 and tumor TNM staging, N staging, lymph nodes resected, and differentiation were well matched in the two groups, except the greatest tumor diameter and $\mathrm{T}$ staging. Although the DP group had larger tumors, which could result in some bias, the two groups were generally 
Table 3 Survival data of the CP group

\begin{tabular}{lllllrl}
\hline ID & Gender & Age (year) & Date of operation & Postoperative hospital stay (day) & Postoperative survival (month) & Chemotherapy \\
\hline Patient 1 & Male & 65 & May 5, 2013 & 14 & 7.1 & NA \\
Patient 2 & Female & 63 & June 27, 2011 & 10 & 83.6 & NA \\
Patient 3 & Male & 76 & June 14, 2010 & 12 & 34.6 & No \\
Patient 4 & Male & 55 & November 12, 2009 & 14 & 48.3 & NA \\
Patient 5 & Male & 70 & May 22, 2014 & 8 & 22.9 & No \\
Patient 6 & Female & 72 & November 12, 2014 & 23 & 20.4 & Yes \\
Patient 7 & Female & 62 & December 18, 2014 & 34 & 20.3 & Yes \\
Patient 8 & Female & 67 & August 11, 2016 & 13 & 18.0 & Yes \\
Patient 9 & Female & 51 & November 17, 2016 & 11 & Yes \\
\hline
\end{tabular}

$N A$, not available

comparable in TNM staging. Hence, it is practicable to compare the prognosis of the two groups. The findings of the present study demonstrated no significant difference in operative time, blood loss, and blood transfusion. Although the CP group had higher overall morbidity, overall POPF, and grade B + C POPF rate, the difference was not statistically significant. Moreover, no difference was found in the DGE, chyle leak, hemorrhage, abdominal collections, pulmonary complications, postoperative hospital stay, readmission, reoperation, and R0 resection rate. Several reasons might be responsible for our result. First, a statistically significant difference was difficult to obtain due to the limited number of CP cases $(n=9)$. Second, most of the published studies focused on $\mathrm{CP}$ resecting benign or low-grade malignant tumors, and these tumors were usually in the soft pancreas, which is a known risk factor for pancreatic fistula. In the present

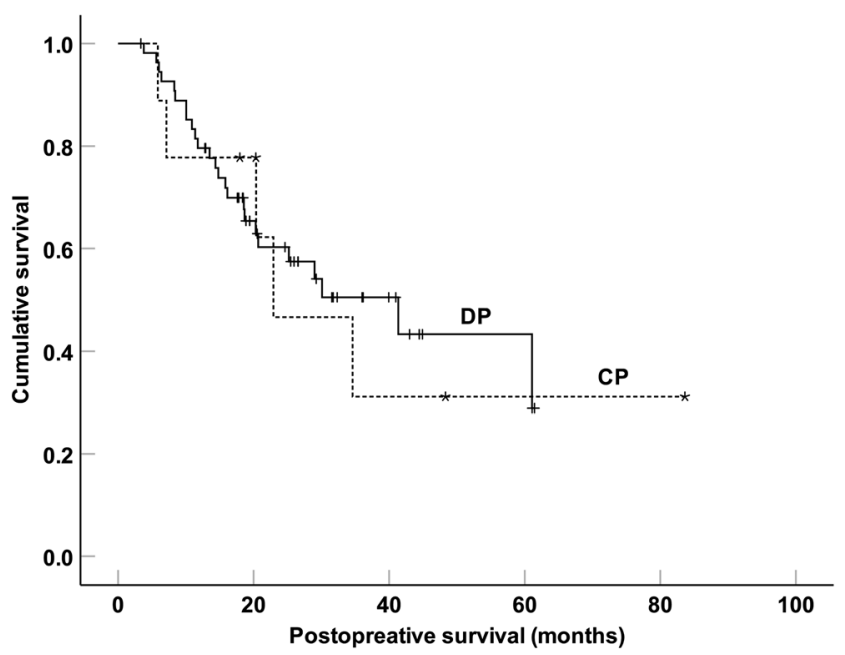

Fig. 1 The Kaplan-Meier survival curves of patients with PDAC undergoing $\mathrm{CP}$ and DP. The CP group had a median postoperative overall survival of 20.4 (12.6-41.5) months, whereas the survival for the DP group was 19.4 (12.9-31.5) months. Log-rank $P=0.842$ series, all patients were diagnosed with PDAC and the parenchyma of the pancreas with PDAC was often hard.

The main benefit of $\mathrm{CP}$ is the preservation of endocrine and exocrine functions because it spares more pancreatic parenchyma than DP. However, limited tissue resection and inadequate lymph node dissection may be potentially noncurative for patients with PDAC $[16,17]$. Thus, $\mathrm{CP}$ is not considered an oncologically appropriate procedure for PDAC. As a matter of fact, very few studies reported treatment of PDAC using $\mathrm{CP}$, especially for early-stage PDAC, let alone high-quality evidence of evidence-based medicine, such as prospective studies or randomized controlled trials.

Given that $\mathrm{CP}$ was a limited resection, $\mathrm{R} 0$ resection should be guaranteed by performing an intraoperative frozen-section biopsy to obtain sound oncologic safety. The DP group had a higher trend of R0 rate compared with the $\mathrm{CP}$ group. Due to the dissatisfactory widespread of intraoperative frozen-section biopsy before and relatively smaller tumors of the $\mathrm{CP}$ group, it was more likely for the surgeons to misjudge that sufficient resection had been made, resulting in significantly higher positive margin in the $\mathrm{CP}$ group. The rate of adjuvant chemotherapy was reported to be different [32-34], varying from 29 to $78 \%$. In this study, the rate of adjuvant chemotherapy was $45 \%$ in the CP group and $67 \%$ in the DP group. In our study, tumors in the $\mathrm{CP}$ group were confined to pancreatic parenchyma with no infiltration to the pancreatic capsule. The findings of this study indicated that for small PDAC (greatest tumor diameter $\leq 2 \mathrm{~cm}$ ) confined to pancreatic parenchyma in the neck of the pancreas, patients undergoing $\mathrm{CP}$ could obtain similar long-term survival as patients treated using DP (20.4 months for CP vs 19.4 months for DP, $P=0.842$ ).

This was the first series to evaluate the safety and feasibility of the CP procedure for PDAC. This retrospective study had some limitations. First, data on adjuvant chemotherapy were incomplete. Their impact on survival was not included in the statistical analysis. Second, the size of patient cohort limited the statistical analysis between the CP and DP groups. 
Table 4 Characteristics of recent studies on CP $(n \geq 30)$

\begin{tabular}{|c|c|c|c|c|c|c|c|c|}
\hline Authors & Year & $\begin{array}{l}\text { Cases of } \\
\mathrm{CP} / \mathrm{DP}\end{array}$ & $\begin{array}{l}\text { Overall } \\
\text { morbidity\% } \\
(\mathrm{CP} / \mathrm{DP})\end{array}$ & $\begin{array}{l}\text { Overall } \\
\text { POPF\% } \\
(\mathrm{CP} / \mathrm{DP})\end{array}$ & $\begin{array}{l}\text { Grade B + C } \\
\text { POPF\% } \\
(\mathrm{CP} / \mathrm{DP})\end{array}$ & $\begin{array}{l}\text { Mortality\% } \\
\text { (CP/DP) }\end{array}$ & $\begin{array}{l}\text { Endocrine } \\
\text { insufficiency\% } \\
\text { (CP/DP) }\end{array}$ & $\begin{array}{l}\text { Exocrine } \\
\text { insufficiency\% } \\
(\mathrm{CP} / \mathrm{DP})\end{array}$ \\
\hline Sauvanet et al. [24] & 2002 & $53 /-$ & $41 /-$ & $30 /-$ & NA & $2 /-$ & $6 /-$ & $8 /-$ \\
\hline Balzano et al. [25] & 2003 & $32 / 21$ & $62 / 29$ & $50 / 14$ & NA & $0 / 0$ & $10 / 15.8$ & $6.2 / 4.8$ \\
\hline Müller et al. [26] & 2006 & $40 / 40$ & $27.5 / 25$ & $7.5 / 10$ & NA & $2.5 / 0$ & $15 / 42$ & $46 / 41$ \\
\hline Crippa et al. [1] & 2007 & $100 / 45$ & $58 / 46.7$ & $44 / 29$ & $17 / 13$ & $0 / 0$ & $4 / 38$ & $5 / 15.6$ \\
\hline Adham et al. [27] & 2008 & $50 /-$ & $38 /-$ & $8 /-$ & NA & $0 /-$ & $0 /-$ & NA \\
\hline Lavu et al. [28] & 2008 & $34 /-$ & $47.1 /-$ & $29.4 /-$ & $11.8 /-$ & NA & $5 /-$ & NA \\
\hline DiNorcia et al. [16] & 2010 & $50 / 50$ & $42 / 40$ & $24 / 20$ & $18 / 14$ & $0 / 0$ & $14 / 46$ & $0 / 0$ \\
\hline Du et al. [29] & 2013 & $36 / 26$ & NA & $42 / 31$ & $17 /-$ & $0 / 0$ & $2.8 / 21.7$ & $8.3 / 8.7$ \\
\hline Goudard et al. [5] & 2014 & $100 /-$ & $72 /-$ & $63 /-$ & $44 /-$ & $3 /-$ & $7 /-$ & $6 /-$ \\
\hline Dokmak et al. [30] & 2017 & $35 / 165$ & $74 / 55$ & $51 / 40$ & $23 / 27$ & $0 / 0$ & NA & NA \\
\hline Iacono et al.* [10] & 2013 & $359 / 480$ & $47.1 / 29.4$ & $30.8 / 14.3$ & NA & $0.9 / 0$ & $5.5 / 23.6$ & 11.9/19.1 \\
\hline Sean et al.* [31] & 2016 & $586 /-$ & $50.3 /-$ & $34.1 /-$ & NA & $0.7 /-$ & $3.2 /-$ & $6.5 /-$ \\
\hline Xiao et al.* [11] & 2018 & $539 / 869$ & $51 / 26$ & $35 / 21$ & NA & $0.5 / 0.1$ & $4 / 31$ & $5 / 13$ \\
\hline
\end{tabular}

$C P$, central pancreatectomy; $D P$, distal pancreatectomy; $P O P F$, postoperative pancreatic fistula; $N A$, not available

*Systematic review and meta-analysis

\section{Conclusions}

$\mathrm{CP}$ is safe for patients with small PDAC at the neck of the pancreas. The rate of postoperative morbidity and clinically significant POPF after CP did not differ from those after DP. Considering the good preservation of pancreatic endocrine and exocrine functions, CP could be considered as an alternative procedure for single small PDAC (greatest tumor diameter $\leq 2 \mathrm{~cm}$ ) confined to pancreatic parenchyma in the neck of the pancreas. This result should be verified by well-designed studies with large samples.

Acknowledgments The authors thank doctor Jin He from The Johns Hopkins Hospital for his professional comments and suggestions for this paper.

Authors' contributions Jishu Wei and Yi Miao participated in study conception and design. Guangfu Wang, Yong Gao, and Lingdi Yin participated in acquisition of data. Yunpeng Peng, Nan Lyu, and Kai Zhang participated in analysis and interpretation of data. Hao Gao and Tongtai Liu participated in drafting of manuscript. Wentao Gao, Junli $\mathrm{Wu}$, and Kuirong Jiang participated in critical revision of manuscript.

Funding information This work was supported by grants from the National Science Foundation of Jiangsu Province (BK20161590) and National Natural Science Foundation of China (81672449).

\section{Compliance with ethical standards}

Conflict of interest The authors declare that they have no conflict of interest.
Ethical approval All procedures performed in studies involving human participants were in accordance with the ethical standards of the institutional and/or national research committee and with the 1964 Helsinki declaration and its later amendments or comparable ethical standards.

Informed consent For this type of study, formal consent is not required.

Open Access This article is distributed under the terms of the Creative Commons Attribution 4.0 International License (http:// creativecommons.org/licenses/by/4.0/), which permits unrestricted use, distribution, and reproduction in any medium, provided you give appropriate credit to the original author(s) and the source, provide a link to the Creative Commons license, and indicate if changes were made.

Publisher's note Springer Nature remains neutral with regard to jurisdictional claims in published maps and institutional affiliations.

\section{References}

1. Crippa S, Bassi C, Warshaw AL, Falconi M, Partelli S, Thayer SP, Pederzoli P, Fernandez-del Castillo C (2007) Middle pancreatectomy: indications, short- and long-term operative outcomes. Ann Surg 246(1):69-76. https://doi.org/10.1097/01.sla.0000262790. 51512.57

2. Nell S, Borel Rinkes IHM, Verkooijen HM, Bonsing BA, van Eijck $\mathrm{CH}$, van Goor H, de Kleine RHJ, Kazemier G, Nieveen van Dijkum EJ, Dejong CHC, Valk GD, Vriens MR (2018) Early and late complications after surgery for MEN1-related nonfunctioning pancreatic neuroendocrine tumors. Ann Surg 267(2):352-356. https://doi. org/10.1097/SLA.0000000000002050

3. Sikkens EC, Cahen DL, de Wit J, Looman CW, van Eijck C, Bruno MJ (2014) Prospective assessment of the influence of pancreatic 
cancer resection on exocrine pancreatic function. Br J Surg 101(2): 109-113. https://doi.org/10.1002/bjs.9342

4. Beger HG, Poch B, Mayer B, Siech M (2018) New onset of diabetes and pancreatic exocrine insufficiency after pancreaticoduodenectomy for benign and malignant tumors: a systematic review and meta-analysis of long-term results. Ann Surg 267(2):259-270. https://doi.org/10.1097/SLA.0000000000002422

5. Goudard Y, Gaujoux S, Dokmak S, Cros J, Couvelard A, Palazzo M, Ronot M, Vullierme MP, Ruszniewski P, Belghiti J, Sauvanet A (2014) Reappraisal of central pancreatectomy a 12-year single-center experience. JAMA Surg 149(4):356-363. https://doi.org/10. 1001/jamasurg.2013.4146

6. Moletta L, Milanetto AC, Vincenzi V, Alaggio R, Pedrazzoli S, Pasquali C (2014) Pancreatic secondary lesions from renal cell carcinoma. World J Surg 38(11):3002-3006. https://doi.org/10.1007/ s00268-014-2672-2

7. Dumitrascu T, Scarlat A, Ionescu M, Popescu I (2017) Central pancreatectomy: an oncologically safe option to treat metastases of other neoplasms of the mid-portion of the pancreas? Ann Hepatobiliary Pancreat Surg 21(2):76-79. https://doi.org/10. 14701/ahbps.2017.21.2.76

8. Iacono C, Ruzzenente A, Bortolasi L, Guglielmi A (2014) Central pancreatectomy: the Dagradi Serio Iacono operation. Evolution of a surgical technique from the pioneers to the robotic approach. World J Gastroenterol 20(42):15674-15681. https://doi.org/10.3748/wjg. v20.i42.15674

9. Xu SB, Zhu YP, Zhou W, Xie K, Mou YP (2013) Patients get more long-term benefit from central pancreatectomy than distal resection: a meta-analysis. Eur J Surg Oncol 39(6):567-574. https://doi.org/ 10.1016/j.ejso.2013.02.003

10. Iacono $\mathrm{C}$, Verlato $\mathrm{G}$, Ruzzenente $\mathrm{A}$, Campagnaro $\mathrm{T}$, Bacchelli $\mathrm{C}$, Valdegamberi A, Bortolasi L, Guglielmi A (2013) Systematic review of central pancreatectomy and meta-analysis of central versus distal pancreatectomy. Br J Surg 100(7):873-885. https://doi.org/ 10.1002/bjs.9136

11. Xiao W, Zhu J, Peng L, Hong L, Sun G, Li Y (2018) The role of central pancreatectomy in pancreatic surgery: a systematic review and meta-analysis. HPB 20:896-904. https://doi.org/10.1016/j.hpb. 2018.05.001

12. Hackert T, Hinz U, Fritz S, Strobel O, Schneider L, Hartwig W, Buchler MW, Werner J (2011) Enucleation in pancreatic surgery: indications, technique, and outcome compared to standard pancreatic resections. Langenbeck's Arch Surg 396(8):1197-1203. https:// doi.org/10.1007/s00423-011-0801-z

13. Cauley CE, Pitt HA, Ziegler KM, Nakeeb A, Schmidt CM, Zyromski NJ, House MG, Lillemoe KD (2012) Pancreatic enucleation: improved outcomes compared to resection. J Gastrointest Surg 16(7):1347-1353. https://doi.org/10.1007/s11605-012-1893-

14. Kaiser J, Fritz S, Klauss M, Bergmann F, Hinz U, Strobel O, Schneider L, Buchler MW, Hackert T (2017) Enucleation: a treatment alternative for branch duct intraductal papillary mucinous neoplasms. Surgery 161(3):602-610. https://doi.org/10.1016/j. surg.2016.09.026

15. Huttner FJ, Fitzmaurice C, Schwarzer G, Seiler CM, Antes G, Buchler MW, Diener MK (2016) Pylorus-preserving pancreaticoduodenectomy ( $p$ p Whipple) versus pancreaticoduodenectomy (classic Whipple) for surgical treatment of periampullary and pancreatic carcinoma. Cochrane Database Syst Rev 2:Cd006053. https://doi.org/10.1002/14651858. CD006053.pub6

16. DiNorcia J, Ahmed L, Lee MK, Reavey PL, Yakaitis EA, Lee JA, Schrope BA, Chabot JA, Allendorf JD (2010) Better preservation of endocrine function after central versus distal pancreatectomy for mid-gland lesions. Surgery 148(6):1247-1254; discussion 12541246. https://doi.org/10.1016/j.surg.2010.09.003
17. Shikano T, Nakao A, Kodera Y, Yamada S, Fujii T, Sugimoto H, Kanazumi N, Nomoto S, Takeda S (2010) Middle pancreatectomy: safety and long-term results. Surgery 147(1):21-29. https://doi.org/ 10.1016/j.surg.2009.04.036

18. Bassi C, Marchegiani G, Dervenis C, Sarr M, Abu Hilal M, Adham M, Allen P, Andersson R, Asbun HJ, Besselink MG, Conlon K, Del Chiaro M, Falconi M, Fernandez-Cruz L, Fernandez-Del Castillo C, Fingerhut A, Friess H, Gouma DJ, Hackert T, Izbicki J, Lillemoe KD, Neoptolemos JP, Olah A, Schulick R, Shrikhande SV, Takada T, Takaori K, Traverso W, Vollmer CR, Wolfgang CL, Yeo CJ, Salvia R, Buchler M (2017) The 2016 update of the International Study Group (ISGPS) definition and grading of postoperative pancreatic fistula: 11 years after. Surgery 161(3):584-591. https://doi. org/10.1016/j.surg.2016.11.014

19. Wente MN, Bassi C, Dervenis C, Fingerhut A, Gouma DJ, Izbicki JR, Neoptolemos JP, Padbury RT, Sarr MG, Traverso LW, Yeo CJ, Buchler MW (2007) Delayed gastric emptying (DGE) after pancreatic surgery: a suggested definition by the International Study Group of Pancreatic Surgery (ISGPS). Surgery 142(5):761-768. https://doi.org/10.1016/j.surg.2007.05.005

20. Besselink MG, van Rijssen LB, Bassi C, Dervenis C, Montorsi M, Adham M, Asbun HJ, Bockhorn M, Strobel O, Buchler MW, Busch OR, Charnley RM, Conlon KC, Fernandez-Cruz L, Fingerhut A, Friess H, Izbicki JR, Lillemoe KD, Neoptolemos JP, Sarr MG, Shrikhande SV, Sitarz R, Vollmer CM, Yeo CJ, Hartwig W, Wolfgang CL, Gouma DJ (2017) Definition and classification of chyle leak after pancreatic operation: a consensus statement by the International Study Group on Pancreatic Surgery. Surgery 161(2): 365-372. https://doi.org/10.1016/j.surg.2016.06.058

21. Wente MN, Veit JA, Bassi C, Dervenis C, Fingerhut A, Gouma DJ, Izbicki JR, Neoptolemos JP, Padbury RT, Sarr MG, Yeo CJ, Buchler MW (2007) Postpancreatectomy hemorrhage (PPH): an International Study Group of Pancreatic Surgery (ISGPS) definition. Surgery 142(1):20-25. https://doi.org/10.1016/j.surg.2007.02. 001

22. Allen PJ, Kuk D, Castillo CF, Basturk O, Wolfgang CL, Cameron JL, Lillemoe KD, Ferrone CR, Morales-Oyarvide V, He J, Weiss MJ, Hruban RH, Gonen M, Klimstra DS, Mino-Kenudson M (2017) Multi-institutional validation study of the American Joint Commission on Cancer (8th edition) changes for $\mathrm{T}$ and $\mathrm{N}$ staging in patients with pancreatic adenocarcinoma. Ann Surg 265(1):185191. https://doi.org/10.1097/sla.0000000000001763

23. Kang CM, Lee JH, Lee WJ (2014) Minimally invasive central pancreatectomy: current status and future directions. J Hepatobiliary Pancreat Sci 21(12):831-840. https://doi.org/10. 1002/jhbp. 143

24. Sauvanet A, Partensky C, Sastre B, Gigot JF, Fagniez PL, Tuech JJ, Millat B, Berdah S, Dousset B, Jaeck D, Le Treut YP, Letoublon C (2002) Medial pancreatectomy: a multi-institutional retrospective study of 53 patients by the French Pancreas Club. Surgery 132(5): 836-843. https://doi.org/10.1067/msy.2002.127552

25. Balzano G, Zerbi A, Veronesi P, Cristallo M, Di Carlo V (2003) Surgical treatment of benign and borderline neoplasms of the pancreatic body. Dig Surg 20(6):506-510. https://doi.org/10.1159/ 000073646

26. Muller MW, Friess H, Kleeff J, Hinz U, Wente MN, Paramythiotis D, Berberat PO, Ceyhan GO, Buchler MW (2006) Middle segmental pancreatic resection: an option to treat benign pancreatic body lesions. Ann Surg 244(6):909-918; discussion 918-920. https://doi. org/10.1097/01.sla.0000247970.43080.23

27. Adham M, Giunippero A, Hervieu V, Courbiere M, Partensky C (2008) Central pancreatectomy: single-center experience of 50 cases. Arch Surg 143(2):175-180; discussion 180-171. https://doi. org/10.1001/archsurg.2007.52

28. Lavu H, Knuth JL, Baker MS, Shen C, Zyromski NJ, Schmidt M, Nakeeb A, Howard TJ (2008) Middle segment pancreatectomy can 
be safely incorporated into a pancreatic surgeon's clinical practice. HPB 10(6):491-497. https://doi.org/10.1080/13651820802356580

29. Du ZY, Chen S, Han BS, Shen BY, Liu YB, Peng CH (2013) Middle segmental pancreatectomy: a safe and organ-preserving option for benign and low-grade malignant lesions. World $\mathrm{J}$ Gastroenterol 19(9):1458-1465. https://doi.org/10.3748/wjg.v19. i9.1458

30. Dokmak S, Fteriche FS, Aussilhou B, Levy P, Ruszniewski P, Cros J, Vullierme MP, Khoy Ear L, Belghiti J, Sauvanet A (2017) The largest European single-center experience: 300 laparoscopic pancreatic resections. J Am Coll Surg 225(2):226-234.e222. https:// doi.org/10.1016/j.jamcollsurg.2017.04.004

31. Ronnekleiv-Kelly SM, Javed AA, Weiss MJ (2016) Minimally invasive central pancreatectomy and pancreatogastrostomy: current surgical technique and outcomes. J Vis Surg 2:138. https://doi. org/10.21037/jovs.2016.07.22

32. Yamamoto T, Yagi S, Kinoshita H, Sakamoto Y, Okada K, Uryuhara K, Morimoto T, Kaihara S, Hosotani R (2015) Longterm survival after resection of pancreatic cancer: a single-center retrospective analysis. World J Gastroenterol 21(1):262-268. https://doi.org/10.3748/wjg.v21.i1.262

33. Ahola R, Siiki A, Vasama K, Vornanen M, Sand J, Laukkarinen J (2017) Patients with resected, histologically re-confirmed pancreatic ductal adenocarcinoma (PDAC) can achieve long-term survival despite T3 tumour or nodal involvement. The Finnish Register Study 2000-2013. Pancreatology : official journal of the International Association of Pancreatology (IAP) [et al] 17(5): 822-826. https://doi.org/10.1016/j.pan.2017.07.192

34. Nakano Y, Kitago M, Shinoda M, Abe Y, Yagi H, Hibi T, Takeuchi A, Aiura K, Itano O, Kitagawa Y (2017) Clinical predictive factors of long-term survival after curative resection of pancreatic cancer: a retrospective study. Cancer Med 6(10):2278-2286. https://doi.org/ 10.1002/cam4.1178 